\title{
Envisioning Design Futures via Practice-led Speculative Design Research
}

\author{
BRAD TOBER, University of Illinois at Urbana-Champaign, USA
}

\begin{abstract}
Some criticisms of the contemporary maker movement (referring to the democratization of various production technologies) have conflated the validity of the making arising from this movement with the utility / commercial potential of said making. However, like pure research in traditional disciplines, the true value of exploratory making - of which practice-led research is a part-without immediate utility or application is in the development of a base for future research to build upon. This paper both establishes a context and proposes a framework for practice-led speculative design research, which positions the designer as an instigator whose work can inform that of both other designers and non-designers (such as those engaged in the maker movement). Such work holds the power to chart the course and ensure the future of the discipline as a whole, and thus should be viewed as an essential component of disciplinary activity.
\end{abstract}

\section{KEYWORDS}

Design futures, speculative design, practice-led research, maker movement.

\section{Introduction}

Design and technology are inextricably linked. History has seen a number of technological shifts with massive disciplinary implications for design - the printing press and the personal computer, for example (Meggs and Purvis 2006, 69 and 488). These shifts have seen the tools conventionally associated with the design process become accessible by more and more individuals, broadening the scope of design and prompting design professionals to reimagine both their disciplinary roles and the potential of these tools (Lupton 1998). Design is in the midst of another such shift, with the maker movement promising to (again) extend the means of design production to nearly everyone. This paper introduces the maker movement, outlines its relation to the contemporary discipline of design, and proposes a framework for practice-led speculative design research through which designers can work to maintain the relevance of their profession in yet another period of technological transition.

\section{The maker movement}

The maker movement refers to the increasing prevalence of technologies that facilitate consumer-level production of artifacts - in essence, enabling a sort of small-scale form of manufacturing. According to Mark Hatch, CEO of TechShop (a US-based chain of workshops providing access to maker-related tools), the maker movement is currently characterized by four trends: increased access to tools, increased access to knowledge, a renewed focus on community resources, and an increased interest in how to make things $(2013,5)$. Maker spaces, like Hatch's TechShop, offer tools like 3D printers, laser cutters, and CNC routers for use by members of the 
general public, enabling those with ideas, but without the means of production, to engage with the process of seeing their ideas become reality (Anderson 2010). At an even smaller scale, however, the rapid decrease in price of these tools is elevating the likelihood of making becoming a household activity. For example, as of the writing of this paper, the Peachy Printerbilled as 'the world's most affordable 3D printer' — was available for preorder on Kickstarter for only US\$100 (Rinnovated 2013).

Elements of the contemporary maker movement can be traced back to the Arts and Crafts movement of the late nineteenth and early twentieth centuries, which was framed as a response to the Industrial Revolution (Zipf 2007, 5). In the context of the DIY counterculture of the later twentieth century, George McKay cites John Vidal, currently environment editor for The Guardian, in noting that ' $[\mathrm{t}] \mathrm{he}$ more that corporations globalize and lose touch with the concerns of ordinary people, the more that the seeds of grass-roots revolt are sown' (1998, 3). A similar resistance to globalization can be observed in the various 'slow' movements, such as with the 'slow food' movement initiated in the 1980s (Andrews 2008). The maker movement reflects these influences through its attempt to reduce, or even remove entirely, the distance (both literally and figuratively) between the manufacturers and users of products.

Clearly, through its appropriation of the conventionally restricted means of production, the maker movement is a democratizing force of the masses. In many ways, the movement closely aligns with the academic ideal of broadly disseminating knowledge. However, there are also a number of concerns, ranging in terms of their appropriateness, that have arisen as a result of the increasing visibility of the maker community. Allison Arieff, editorial director for the San Francisco Planning and Urban Research Association and an architecture / design writer for The New York Times, has taken issue with the seemingly superfluous production that the maker movement has enabled (2014). Arieff recognizes the potential of the maker movement in terms of supporting craft and the do-it-yourself mentality, but overly emphasizes the production aspect of the movement at the expense of its significant design aspect, conflating the validity of production with its utility. This is problematic, as it reduces design to a mere agent of consumption - a disciplinary characterization that many contemporary designers have long been attempting to distance themselves from.

\section{Contemporary design}

A traditional characterization of design, as suggested by AIGA (the professional association for design in the United States) fellow and medalist Meredith Davis, addresses 'artifacts, objects, spaces, and messages where the concern is often function [and the] formal qualities of things' (Coulter 2014). Such a perspective, with its focus on both function and things, aligns with Arieff's emphasis on the utility of making and clearly positions the designer as an agent of consumption. However, this is far from a disciplinary characterization that most contemporary designers adhere to. Designers, perhaps most visibly through the several iterations of the First Things First manifesto (in 1964, 2000, and again in 2014), have expressed a wish to return to a more human-centered approach to design. Davis notes this through her observation of a disciplinary shift from 'designing objects to [...] designing behavior' (Coulter 2014). 
Arieff states, 'there's a role for designers and makers (and yes, even entrepreneurs) of stuff - a really important one,' but fails to describe exactly what that role is (2014). She does, however, touch upon one of the more serious issues (at least, from a disciplinary perspective) with the maker movement - that the democratization of design tools risks excluding designers from the design process. If designers fail to capitalize on the potential of the technology surrounding the maker movement, it is inevitable that non-designers will - creating work that society accepts as design and possibly weakening the role of the designer. This is, of course, not unlike the 1980s, when 'the rejection of [the personal computer] by some designers [...] prompted a questioning of the role of design in society by non-designers, particularly those who believed that, by using a desktop publishing application, they could produce work rivaling that of professionals' (Tober 2011, 31). Thus, contemporary designers must take charge by recognizing, respecting, and engaging with the maker movement.

\section{A new role for designers}

One approach for design engagement with the maker movement involves conceptualizing the role Arieff envisions for the designer as, perhaps ironically, one which encourages exploratory making - of which practice-led research is a part—without immediate utility or application, the very form of production she argues against. Corresponding forms of production, as design practice, closely align with UK-based design firm Dunne \& Raby's concept of critical design, which is described as using 'speculative design proposals to challenge narrow assumptions, preconceptions, and givens about the role [designed works] play in everyday life' (2007). Here, the term speculative can be taken to refer to the fact that critical design is explorative, experimental, and does not serve an end-user (or consumer) audience in the same way that commercial design work might. Speculative design asks questions and proposes answers (which may or may not be correct), but does not attempt to identify or prescribe singular solutions.

A typical audience for speculative design consists of, as it intends to provoke, other designers: those currently working in the field and those entering it in the near future. Accordingly, speculative practice is sometimes (disparagingly) referred to as 'design for designers' (Malpass 2013, 335). For this reason, and while Dunne \& Raby note that 'all design to some extent is future oriented' (2013, 3), speculative design is particularly forward-looking, as it must anticipate upcoming trends and engage with them in a way that prepares them for use by other designers in a timely fashion. This conceptualization of speculative design frames the critical practitioner as one who develops a base framework for practice that other designers can develop further, mirroring the way in which a scientist might conduct pure (or basic) research to establish a foundation for other scientists to subsequently build upon.

\section{A maker-based framework for speculative design}

As a response to the maker movement's democratization of design tools, one practical implication of a designer's emergent practice of speculative design may be that he or she transitions from solely executing processes to also mediating them. Most conventional characterizations of design incorporate the recognition that the work designers do follows some sort of process (Howard et al. 2008, 161). Design mediation (Tober 2011, 29) involves the development, implementation, and control of metaprocesses: higher-level processes that govern 
multiple, lower-level processes. This means that designers practicing speculatively may find themselves (and their design work) more focused on influencing the processes of other designers, affecting how individual designers work (at a micro level) and shaping the discipline as a whole (at a macro level). Davis hints at this when she discusses the relatively recent ideas of 'design for conversation' and designing for 'platforms on which others build applications, service ecologies, and communities' (Coulter 2014). Lorraine Wild, also an AIGA medalist, designer, and educator, relates craft - an activity relevant to the aims of the maker movement - to speculative design by 'equat[ing] investigation with meaning' (1998, 20). Furthermore, Johan Redström, head of research at the Umeå Institute of Design, supports the idea that speculative engagement with maker-oriented technology (when viewed as material) holds great potential for shaping the discipline by suggesting that 'the emergence and continuous development of new materials have [...] played a central role in the evolution of design as they challenge existing notions of form, expression, aesthetics, and what sorts of objects in general can be created' $(2005,42)$.

These realizations point to speculative designers being positioned to develop the tools that other designers use to facilitate their design processes, and suggests the necessity for designers to stake a claim in the development of maker-related technologies. However, professional designers comprise only a small fraction of the maker movement, and so the work speculative designers perform in this area has implications for non-designers as well. Regardless, designers practicing speculatively hold the power to steer the maker movement in a direction that maintains the professional designer's relevancy. There are at least three specific opportunities through which this might occur: (1) identifying and exploring (through practice-led research activity) new technologies ripe for democratization, (2) developing new and intuitive ways of making technologies more approachable by the maker community, and (3) improving the quality of resources available to the maker community.

\section{Exploring new technologies}

Continued technological development has led to a significant decrease in the expense of building start-up companies (Hatch 2013, 112). Consequently, more and more entrepreneurs are taking advantage of the opportunity to pursue the development of their ideas and see them turn into marketable products. The scale of these endeavors, however, is still relatively small and is characterized by a limited access to resources. For this reason, many maker-related technologies (particularly those that are digitally-based) are heavily dependent on the larger maker community for realizing the full potential of their platform - especially in terms of building software that enables the functionality of hardware. Here is where a great deal of speculative design potential lies, most notably for the designer with skill in programming and computer code. This expands upon a conventional understanding of the maker movement in regards to the physicality of many of its products, but the core principles of the movement remain the same in this new context.

One example of such technology is the Leap Motion Controller by Leap Motion, Inc., a San Francisco-based start-up founded in 2010. This human computer interface hardware promises users the ability to 'control [their] computer[s] in a whole new way [by tracking] both hands and all 10 fingers with incredible speed - so [one] can play, create, and explore without touching anything' (Leap Motion 2015). The Leap Motion Controller was released in 2013 to mixed reviews. While it is easy to imagine the potential of such a device in its presentation of a new 
paradigm for digitally interactive experiences, reviewers noted that early applications that leveraged the controller were 'opportunistic without being truly innovative' (Etherington 2013). However, with access to the software development kit (SDK), a suite of code-based tools for accessing the functionality of the controller, designers have the chance to explore what it means to innovate within the context of developing a new form of computer interface. In this case, design research might involve speculatively proposing answers to questions such as, 'How does a user control an interface gesturally?' or, 'What implications does this hardware have for the visual components of an interface design?'

Similarly, the Sifteo Cubes interactive gaming platform (Merrill et al. 2012, 1015), the latest iteration of which was released in 2012 by Sifteo, Inc. (another San Francisco-based startup), represents another area of potential for speculative (interface) design investigation. The Sifteo base stores and runs software built for the platform, connecting wirelessly to up to twelve 1.7inch square cubes. The cubes each feature a touch sensitive LCD, an accelerometer, and sensors so that the cubes know when and where they are in contact with one another. The small scale of this hardware restricts its processing power, presenting a challenge for designers working with the Sifteo SDK; design engagement with the platform is a foundational exercise in the principle of economy. Additionally, designing for and with the Sifteo Cubes is a prime example of one of the risks of working speculatively - the company was acquired in 2014 and has ceased development on the platform (Sifteo 2014). While this does not discount any work done to engage with the Sifteo Cubes, it can be a discouraging outcome for those designers who have focused a great deal of their efforts in a particular area.

\section{Making existing technologies more approachable}

Many technologies with maker potential are not the products of start-ups; rather, they are relatively mature offerings from large, established organizations. In many cases, however, these technologies are complex and unapproachable by the vast majority of those in the maker community - the knowledge and skills that they require are too specialized. Speculative design can investigate the conceptual nature of these types of technologies and work to translate them into new platforms built upon more accessible media and technologies. Designers working in this way are fully embracing their roles as mediators, both in the conventional sense and in the way described earlier in this paper.

Mobile app development represents one area where such opportunities for speculative designers exist. Conventional approaches to development for the leading mobile platforms-Apple's iOS and Google's Android-require advanced knowledge of sophisticated programming languages that are well outside of the skill set of the typical maker. One approach to making the mobile app space more accessible can be seen in the number of frameworks being developed using the standards-based technologies of the web: HTML, CSS, and JavaScript. Ionic, one of these frameworks, is described as a 'beautiful, open source front-end SDK for developing hybrid mobile apps with HTML5' (DriftyCo 2015). This platform makes developing a mobile app a more realistic goal for a much broader maker audience. DriftyCo, the start-up software company that created the Ionic framework, is notably characterized by a significant emphasis on design. 


\section{Improving the quality of maker resources}

While the maker movement certainly is characterized by its tools and technologies, its community is just as critical. Thus, speculative designers working within the movement may not solely be concerned with maker tools in a technological sense - there is also a need to consider the social value of these tools and what makers do with them. This community focus and interest in increasing access to knowledge has resulted in a number of platforms enabling makers to share the fruits of their labors. One such platform is Thingiverse, a 'thriving design community for discovering, making, and sharing 3D printable things' (MakerBot 2015), while another is OpenProcessing, an 'online community platform devoted to sharing and discussing Processing [(a programming language and environment for people who want to program images, animation, and interactions)] sketches in a collaborative, open source environment' (Ascioglu 2011). While the motivation behind the existence of these platforms varies-Thingiverse is arguably a facet of MakerBot's marketing strategy, for example - it is clear that designers have a role in facilitating (and mediating) the maker-to-maker interaction that they encourage. Additionally, by engaging as makers themselves, speculative designers can strengthen these communities by contributing high quality work of their own, setting an example for other (non-designer) makers to emulate and / or follow.

\section{Conclusion}

This paper presents a framework for contemporary design engagement with the maker movement by framing practice-led speculative design research as a process of exploratory and experimental making. The increasing democratization of production tools and technologies, such as those associated with the maker movement, continues to threaten the conventional role of the designer. Thus, the role of the designer must evolve. One such possible role takes a meta view of the design process and is one in which the designer is primarily concerned with the development of maker-oriented tools and technologies. This may take the form of exploring the design potential of tools, mediating the relationship between tools and their users, or using tools alongside other (non-designer) users in the interest of community-building. These activities are all highly dependent on the specialized knowledge and experience that professional designers have, and they uniquely position designers to not only maintain their relevance in the present, but also shape the future of design.

\section{References}

Anderson, C. (2010) 'In the Next Industrial Revolution, Atoms Are the New Bits,' Wired [online] 25 January. Available at http://www.wired.com/2010/01/ff newrevolution. Accessed 15 May 2015

Andrews, G. (2008) The Slow Food Story: Politics and Pleasure, Montréal: McGill Queen's University Press

Arieff, A. (2014) 'Yes We Can. But Should We? The unintended consequences of the Maker movement,' [online] 15 September. Available at https://medium.com/re-form/just because-youcan-doesnt-mean-you-should-252fdbcf76c8. Accessed 15 May 2015

Ascioglu, S. (2011) 'OpenProcessing,' [online]. Available at http://openprocessing.org. 
Accessed 15 May 2015

Barnbook, J. et al. (1999) 'First Things First Manifesto 2000,' Emigre 51 [online]. Available at http://emigre.com/Editorial.php?sect=1\&id=14. Accessed 15 May 2015

Coulter, B. (2014) 'Mapping the Field of Design: Part 1 of an Interview with Meredith Davis,' [online] 1 September. Available at https://raleigh.aiga.org/mapping-the-field-of design. Accessed15 May 2015

Dunne, A. and Raby, F. (2007) 'Critical Design FAQ,' [online]. Available at http://www.dunneandraby.co.uk/content/bydandr/13/0. Accessed 15 May 2015

Dunne, A. and Raby, F. (2013) Speculative Everything, Cambridge: MIT Press

DriftyCo. (2015) 'Ionic: Advanced HTML5 Hybrid Mobile App Framework,' [online]. Available at http://ionicframework.com. Accessed 15 May 2015

Etherington, D. (2013) 'Leap Motion Launches With Limited Appeal, But It Could Be A Ticking Time Bomb Of Innovation,' TechCrunch [online] 22 July. Available at http://tcrn.ch/1322QTI. Accessed 15 May 2015

Garland, K. (1964) First Things First, London: Goodwin Press

Hatch, M. (2013) The Maker Movement Manifesto: Rules for Innovation in the New World of Crafters, Hackers, and Tinkerers, New York: McGraw-Hill

Howard, T., Culley, S., and Dekoninck, E. (2008) 'Describing the creative design process by the integration of engineering design and cognitive psychology literature,' Design Studies, Volume 29, Issue 2, 160-180

Leap Motion, Inc. (2015) 'Leap Motion,' [online]. Available at https://www.leapmotion.com. Accessed 15 May 2015 Lupton, E. (1998) 'Design and Production in the Mechanical Age,' in D. Rothschild, E. Lupton, and D. Goldstein (eds), Graphic Design in the Mechanical Age: Selections from the Merrill C. Berman Collection, New Haven: Yale University Press, pp. 50-81, [online]. Available at http://elupton.com/2009/10/design-and-production-in-the-mechanical-age. Accessed 15 May 2015

MakerBot Industries, LLC. (2015) 'Thingiverse,' [online]. Available at http://www.thingiverse.com. Accessed 15 May 2015

Malpass, M. (2013) 'Between Wit and Reason: Defining Associative, Speculative, and Critical Design in Practice,' Design and Culture, Volume 5, Issue 3, 333-356

McKay, G. (1998) DIY Culture: Party \& Protest in Nineties Britain, London: Verso 
Meggs, P. and Purvis, A. (2006) Meggs' History of Graphic Design, Hoboken: Wiley

Merrill, D., Sun, E., and Kalanithi, J. (2012) 'Sifteo Cubes,' CHI'12 Extended Abstracts On Human Factors in Computing Systems, 1015-1018

Peters, C. (2014) 'First Things First 2014,' [online] 4 March. Available at http://firstthingsfirst2014.org. Accessed 15 May 2015

Redström, J. (2005) 'On Technology as Material in Design,' Design Philosophy Papers, Volume 3, Issue 2, 39-54

Rinnovated Design (2013) 'The Peachy Printer,' [online] 20 September. Available at https://www.kickstarter.com/projects/117421627/the-peachy-printer-the-first-103d printerand-sc. Accessed 15 May 2015

Sifteo, Inc. (2014) 'Sifteo,' [online]. Available at http://www.sifteo.com. Accessed 15 May 2015

Tober, B. (2011) New Tools of the Trade: An Exploration of Interactive Computational Graphic Design Processes, Toronto: York University

Wild, L. (1998) 'The Macramé of Resistance,' Emigre 47, 15-23

Zipf, C. (2007) Professional Pursuits: Women and the American Arts and Crafts Movement, Knoxville: University of Tennessee Press

Brad Tober, an Assistant Professor of Graphic Design at the University of Illinois at UrbanaChampaign, is a designer, educator, and researcher whose work explores the potential of emerging code-based and interactive visual communication technologies, with the objective of identifying and investigating their relationships to design practice and pedagogy. His practice-led research entity, the Experimental Interface Lab, is characterized by a speculative approach to design (a manifestation of pure research) that recognizes that forms of and methodologies for contemporary practice that spans design and technology are best developed through fundamentally flexible and exploratory processes. Brad holds an MDes from York University (Toronto, Canada), a BFA in graphic design from the Savannah College of Art and Design, and a BA in mathematics from the University at Buffalo.

E-mail: btober@illinois.edu 